\title{
Cerebellar Infarct Accompanied by Acute Hydrocephalus: A Case Report of 1-Year Follow-up in Rural Neurosurgical Practice
}

\author{
Reza Akbar Bastian ${ }^{1 *}$ D, Rachmat Andi Hartanto ${ }^{1}$, Rohmania Setiarini ${ }^{2}$ \\ ${ }^{1}$ Department of Surgery, Division of Neurosurgery, Universitas Gadjah Mada, Special Region of Yogyakarta, Indonesia; \\ ${ }^{2}$ Department of Neurology, Al Azhar Islamic University, Dr. Yuliddin Away General Hospital, South Aceh, Indonesia
}

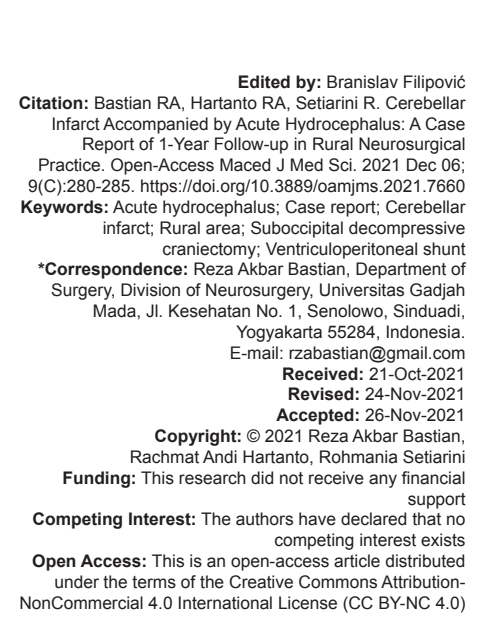

Introduction

Cerebellar infarctions account for about $2-3 \%$ of all ischemic strokes [1], [2], [3]. Massive cerebellar edema with acute hydrocephalus due to brainstem compression or compression of the cerebrospinal fluid (CSF) flows is a rare manifestation of posterior circulation stroke and one of the most threatening complications in cerebellar infarct, which may lead to transforaminal and upward transtentorial herniation [4], [5]. Patients with cerebellar infarcts first presented with initial symptoms, including dizziness, nausea, vomiting, unsteady gait, and headache [6], and might develop significant massive cerebellar edema that usually presents with an altered level of consciousness that typically occurs within 1-7 days, with a mean peak of 3 days [7]. However, sometimes, there are some cases called malignant infarct, which explain the existence of massive edema that appears within $48 \mathrm{~h}$ of ictus [8], and one of the factors in the development of massive edema is the presence of a hypoplastic or cranial venous drainage occlusion [9]. In the development of dealing with ischemic stroke cases, the handling of patients with intravenous thrombolysis with recombinant tissue plasminogen activator (rtPA) within $4.5 \mathrm{~h}$ of the onset symptom is said to provide good clinical development results [10]. However, not all regions have such facilities, especially rural areas, which will have an impact that increases the morbidity and mortality rate [11]. Patients with infarction in the cerebellum have better outcomes compared with infarcts in other locations [12]. Nevertheless, critical decisions and appropriate surgical measures must be taken to prevent lethal complications. Surgery by performing decompressive craniotomy in the posterior fossa accompanied by expanded duraplasty and with/without ventricular drainage is the best choice in the management of this case [4].

\section{Case History}

\section{Clinical characteristics}

A 59-year-old male patient was brought to the emergency room (ER) with a sudden headache and 
followed by dizziness, vomiting, and loss of balance. On arrival, he was still conscious (Glasgow Coma Scale [GCS] 15/15). His vital sign was unremarkable, except for the blood pressure (i.e., 150/90 $\mathrm{mmHg}$ ). Both of his pupils were normal in size and reactive. However, he developed ataxia of the trunk with a tendency to fall toward the left. Muscle strength was normal in all extremities. He was a smoker and had a history of hypertension with irregular use of antihypertensive drugs, but there was no history of STEMI (ST elevation myocardial infarction) or atrial fibrillation.

The patient was then treated in the ward with close observation. About $36 \mathrm{~h}$ after initial treatment, the patient's level of consciousness began to decrease (GCS 7/15), accompanied by an increase in blood pressure $(170 / 98 \mathrm{mmHg})$. Computerized tomography (CT) scan was performed to evaluate the progress of the patient's disease.

\section{Radiological features}

A CT scan of the brain in ER was performed $4 \mathrm{~h}$ after ictus, showing a slightly hypodense lesion in the left cerebellum, without accompanying edema, and signs of hydrocephalus (Figure 1).

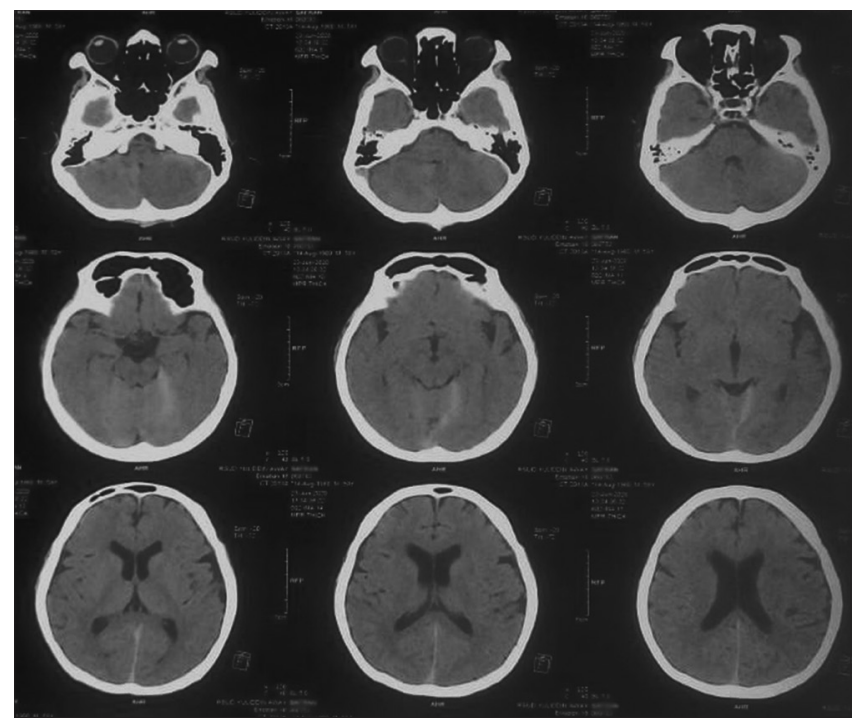

Figure 1: Non-contrast head computerized tomography scan, $4 \mathrm{~h}$ post-ictus, slightly hypodense lesion in the left cerebellum without sign of hydrocephalus

A CT scan of the brain evaluation was then performed after $36 \mathrm{~h}$ following the initial management on the ward when the patient was showing some signs of clinical deterioration. It showed a hypodense lesion in the left cerebellum which corresponds to the territory of the superior cerebellar artery that is posterior circulation. This was also accompanied by signs of compression to the brainstem and the fourth ventricle, as well as the development of signs of hydrocephalus that was characterized by a widening temporal horn, the third ventricle, and ballooning of the lateral ventricles (Figure 2).

\section{evaluation}

\section{Surgical finding and post-operative}

Suboccipital decompressivecraniectomy (SDC) with expanded duraplasty and ventriculoperitoneal (VP) shunt insertion was performed. A midline incision was made approximately $4 \mathrm{~cm}$ above the inion to the spinous process of VC2. Harvesting of the fascia was carried out to prepare for the duraplasty procedure. Two burr holes on the occipital bone were made, then followed by thinning of the bone with high-speed drill and craniectomy using Leksell and Kerrison rongeurs. After the bone was removed, the dura mater appeared tense and did not show any presence of pulsations. Before the dura incision was performed, we performed VP shunt insertion using Frazier's point as the entry point. After CSF was diverted, a Y-shaped incision was performed on the dura, and the necrotic cerebellum parenchyma came out spontaneously. Strokectomy was done, then continued with duraplasty using fascia as a replacement. The procedure was completed in 150 min without any complications during the operation. Postoperatively, the patient was treated in the intensive care unit (ICU) with improvement in GCS 13/15. Patients were treated for a day in ICU and subsequently transferred to the ward on the next day with clinical improvement. In the ward, the patient complained of dizziness and pain in the surgical wound. Both were conservatively managed. On day 3 , the patient complained of double vision when seeing with both eyes, with improvement in headache and dizziness. We suspected the patient with bilateral sixth nerve palsy, which we managed conservatively. The patient was discharged on the $5^{\text {th }}$ day. During the treatment, the patient did not experience fever, CSF leakage, and other complications.

\section{Patient follow-up}

During the follow-up, 1 week after hospital discharge, the patient visited the outpatient clinic without any neurological deficits and improvement in the sixth nerve paresis. We evaluated the wound and the stitches were removed. Four months after surgery, the patient visited the outpatient clinic with dizziness but without any neurological deficits, we performed a head CT evaluation with a favorable result (Figure 3). One year after surgery, the patient visited the outpatient clinic without any neurological deficits, we performed a head CT evaluation to ascertain the progress of his hydrocephalus and the result is remarkable (Figure 4).

\section{Discussion}

The management of patients with cerebellar infarct remains a challenge for the physician because the patients usually present with non-specific complaints which 


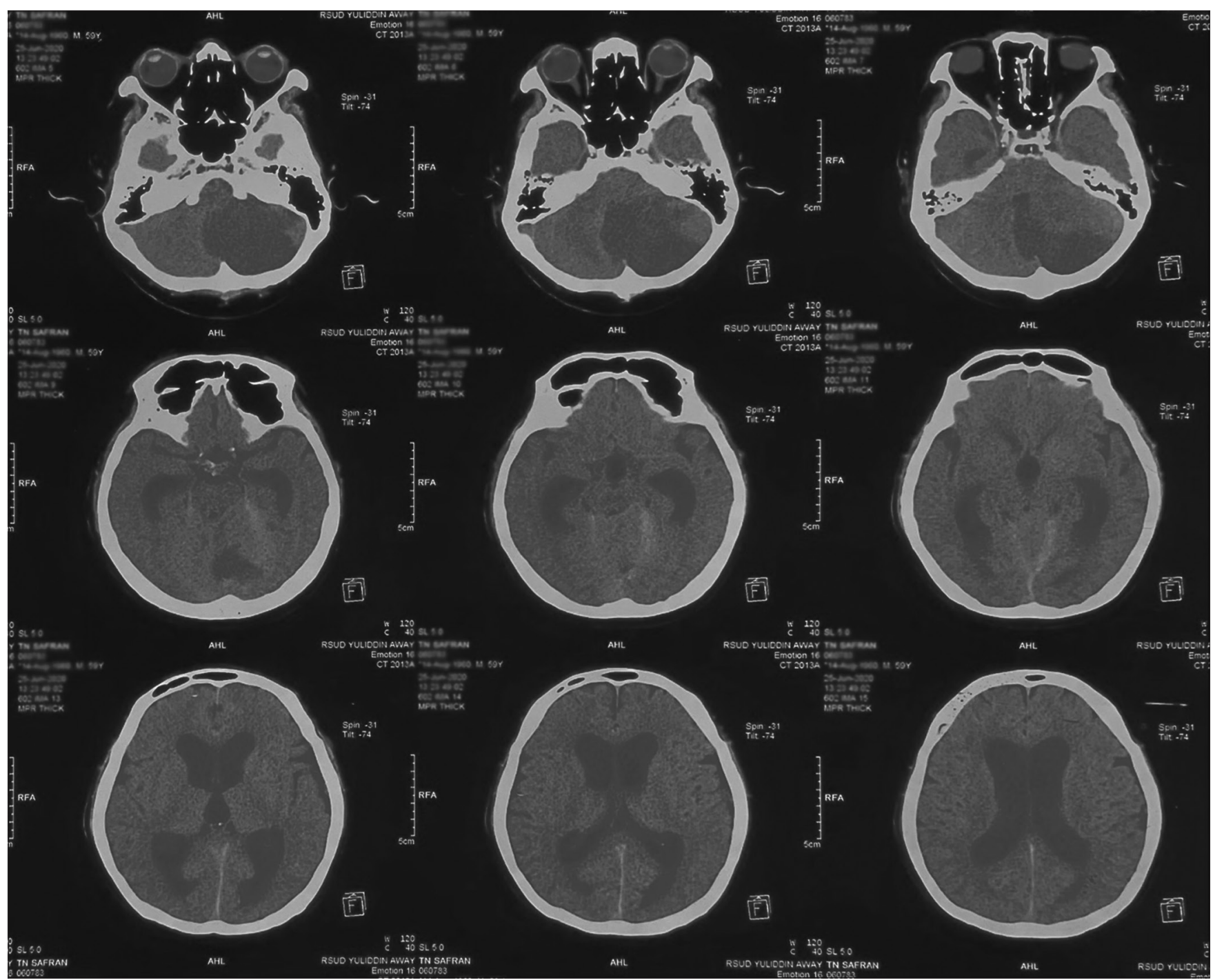

Figure 2: Non-contrast head computerized tomography scan, $36 \mathrm{~h}$ post-ictus, infarct area of the left cerebellar with massive edema accompanied by hydrocephalus

continue until the patients lost consciousness [8]. Even if in the conscious condition, the patient required treatment in the stroke unit or neuro-ICU [4] and is medically treated with anti-thrombolytic intravenous therapy to improve the condition [8]. Brain CT scan sometimes does not show a sign of the infarction if it is done several hours after ictus. The magnetic resonance imaging examination with DWI sequences tends to be superior in this case and also as an assessment of the infarction degree when endovascular procedures are to be performed [13], [14], however, to perform such measures in a rural area with minimal facilities is complicated.

\section{Surgical consideration}

SDC with expanded duraplasty and VP shunt insertion was performed. Postoperative evaluation shows that satisfactory results with rapid resolution of GCS were seen at follow-up after surgery. Four months and 1-year follow-up evaluations also showed remarkable outcomes.
Infarct in the posterior fossa is unique and the surgeon is faced with the possibility of worsening conditions from several mechanisms. First, the compression of the brainstem by the lesion could lead to transforaminal and upward transtentorial herniation. Second, compression of CSF flows might produce secondary obstructive acute hydrocephalus, which subsequently suppresses the brainstem and also might trigger transforaminal and upward transtentorial herniation or a mixture of both. In this case, emergency management must be taken [15].

Conservative management is not recommended in cases with severe mass effects, which tend to give unsuccessful in clinical practice. On the other hand, surgical treatment is widely accepted. One study mentioned a high survival rate in patients undergoing surgery, specifically around $81.6 \%$ in patients who underwent external ventricular drainage (EVD), $76.8 \%$ in patients who underwent SDC, and $77.5 \%$ who underwent EVD and SDC [4]. The other case report also reported a good outcome in the patient with cerebellar infarction complicated with acute hydrocephalus that underwent VP only [16] and SDC with VP shunt [5]. 


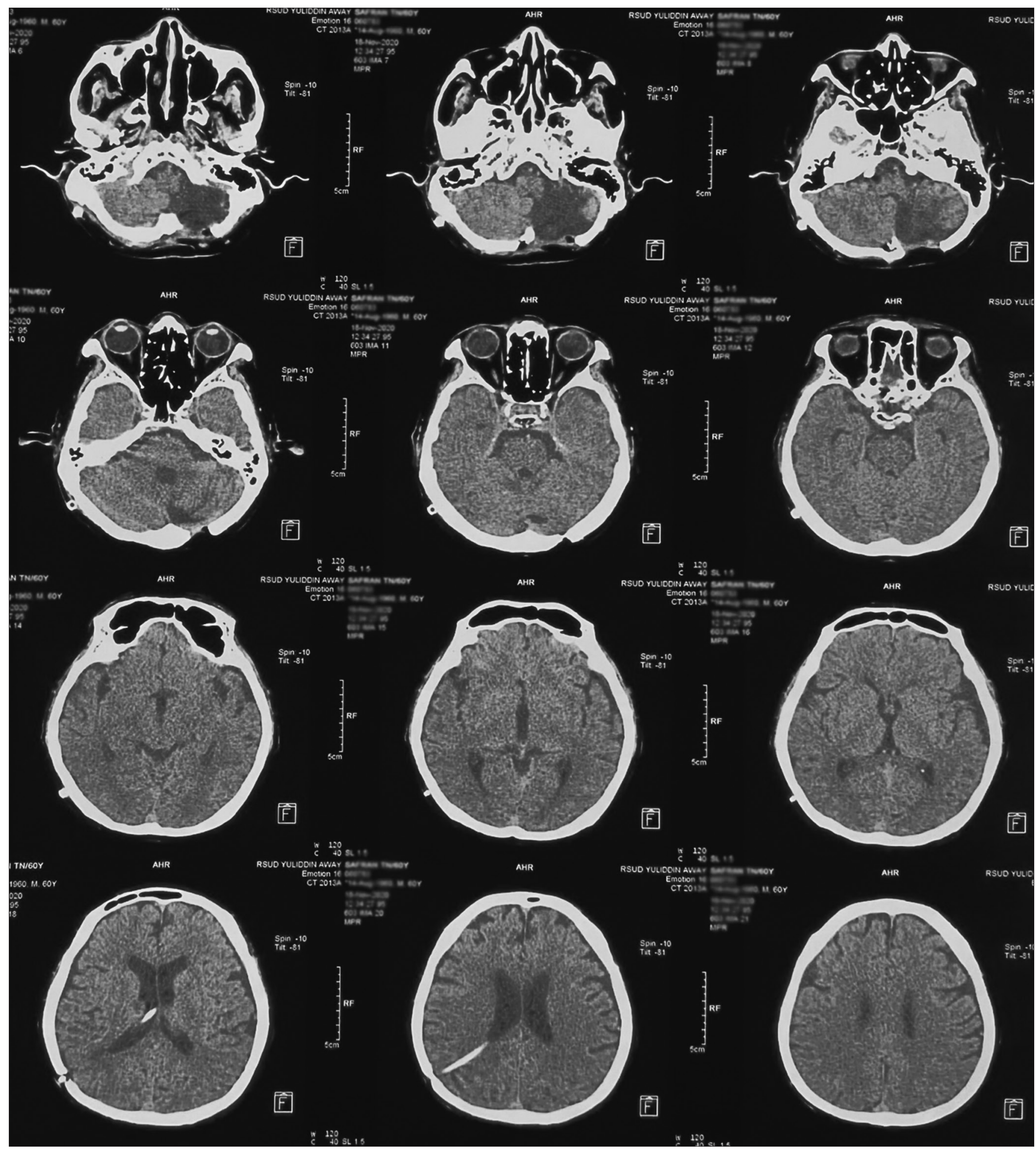

Figure 3: Non-contrast head computerized tomography scan 4 months after surgery, hydrocephalus was resolve with proximal catheter on the right, and encephalomalacia in the left cerebellum

The main concept of the procedures in patients with cerebellar mass effect is decompression of the posterior fossa to prevent the brainstem compression and the occurrence of transforaminal herniation. Furthermore, ventricular drainage with VP shunt is essential to release the high intracranial pressure in the supratentorial compartment. However, such a procedure should be performed after the pressure on the posterior fossa is reduced to prevent upward transtentorial herniation because of immediately significant pressure changes between the infratentorial and supratentorial compartments [15].

\section{Regional referral rural hospital}

This case occurred in Dr. Yuliddin Away General Hospital, Tapak Tuan, a district hospital in South Aceh which was located about $440 \mathrm{~km}$ from Banda Aceh, the capital city of Aceh Province, Indonesia. This hospital 


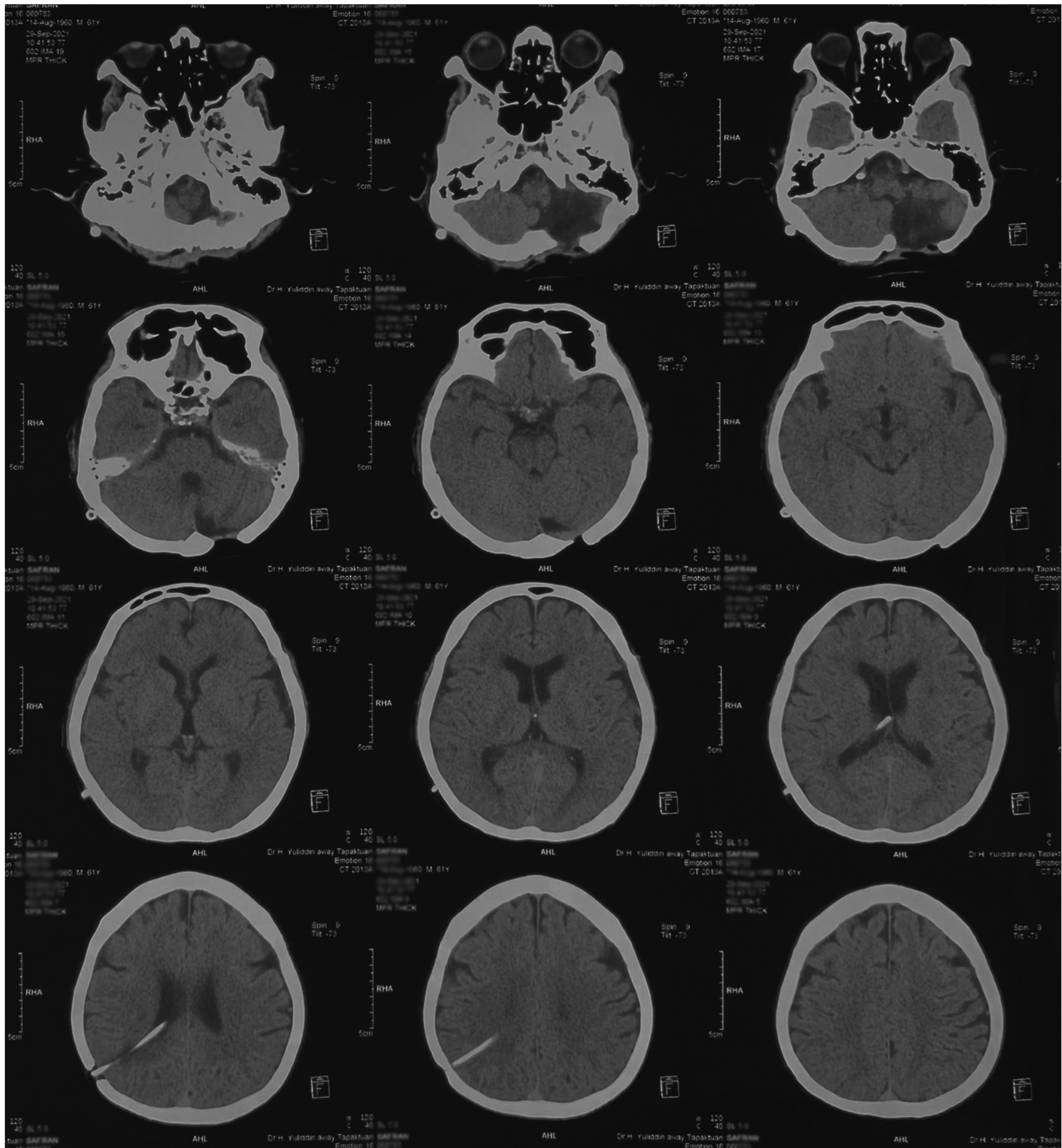

Figure 4: Non-contrast head computerized tomography scan 1 year after surgery

is a regional referral rural hospital from three districts around it (Subulussalam General District Hospital, Aceh Singkil General District Hospital, and Simeulue General District Hospital) with a total population of four districts which were 536.827 people [17], [18]. We started neurosurgical services in April 2019 to reduce disparity in neurosurgery health services in Indonesia, particularly in Aceh, with collaboration among Neurosurgery Division of Universitas Gadjah Mada, local government, health insurance, and other institutions. Neurosurgical services provide by a senior neurosurgical resident under supervision by consultant neurosurgeons on the whole process of services [18]. Nevertheless, this is certainly full of great challenges to start neurosurgery services in rural setting, these challenges include minimal facilities, infrastructure, and lack of resources, particularly related to neurosurgical services, such as having only one neurologist, without neuro nurses, neurophysiotherapists, neurophysiology, and also without improper neurointensive care and neuromonitoring.

The option to transfer the patient to another hospital with a better facility could make him lose the 
golden period of brain and life-saving, and also was denied by the family members due to the long transport distance (estimated $9 \mathrm{~h}$ away by ground ambulance).

\section{Conclusion}

The patients with cerebellar infarct require close observation for general condition and neurological signs in the stroke unit or neuro-ICU, even when there is no life-threatening condition at initial presentation in the ER. Inevitably, this is a challenge for rural hospital areas, to improve the practice of neurosurgical service and improve the standard of care in rural settings. Collaboration among hospitals, government, and related institutions is needed to improve facilities, infrastructure, and training programs among healthcare staffs, to improve the quality of neurosurgery services to reduce morbidity and mortality. In patients in whom surgery is indicated, the choice of surgery with SDC with expanded duraplasty and ventricular drainage (EVD or VP shunt) might provide satisfactory results.

\section{Acknowledgments}

The authors would like to thank to Wiryawan Manusubroto for suggestion and informative discussion and the editor for the contributions to this manuscript.

\section{References}

1. Kumral E, Kisabay A, Ataç C, Calli C, Yunten N. Spectrum of the posterior inferior cerebellar artery territory infarcts. Clinicaldiffusion-weighted imaging correlates. Cerebrovasc Dis. 2005;20(5):370-80. https://doi.org/10.1159/000088667 PMid: 16205055

2. Kumral E, Kisabay A, Ataç C. Lesion patterns and etiology of ischemia in the anterior inferior cerebellar artery territory involvement: A clinical-diffusion weightedMRI study. Eur J Neurol. 2006;13(4):395-401. https://doi. org/10.1111/j.1468-1331.2006.01255.x

PMid:16643319

3. Ganapathy K, Girija T, Rajaram R, Mahendran S. Surgical management of massive cerebellar infarction. J Clin Neurosci. 2003;10(3):362-4. https://doi.org/10.1016/ s0967-5868(02)00321-1

PMid: 12763347

4. Neugebauer H, Witsch J, Zweckberger K, Jüttler E. Spaceoccupying cerebellar infarction: Complications, treatment, and outcome. Neurosurg Focus. 2013;34(5):E8. https://doi.
org/10.3171/2013.2.FOCUS12363

PMid:23634927

5. Rosyidi RM, Priyanto B. Cerebellar infarction complicated with acute hydrocephalus. Int J Res Med Sci. 2019;7(3):948. https:// doi.org/10.18203/2320-6012.ijrms20190955

6. Wang C, Xu DM, Ma LY, Wang C, Xu D, Ma L. Magnetic resonance imaging and clinical findings of pseudotumor-type cerebellar infarction. Int J Clin Exp Med. 2018;11(1):231-6.

7. Jauss M, Krieger D, Hornig C, Schramm J, Busse O. Surgical and medical management of patients with massive cerebellar infarctions: Results of the German-Austrian cerebellar infarction study. J Neurol. 1999;246(4):257-64. https://doi.org/10.1007/ s004150050344

PMid:10367693

8. Hacke W, Schwab S, Horn M, Spranger M, De Georgia M, von Kummer R. "Malignant" middle cerebral artery territory infarction: Clinical course and prognostic signs. Arch Neurol. 1996;53(4):309-15. https://doi.org/10.1001/ archneur.1996.00550040037012

PMid:8929152

9. Yu W, Rives J, Welch B, White J, Stehel E, Samson D. Hypoplasia or occlusion of the ipsilateral cranial venous drainage is associated with early fatal edema of middle cerebral artery infarction. Stroke. 2009;40(12):3736-9. https://doi.org/10.1161/ STROKEAHA.109.563080

PMid:19762692

10. Moussaddy A, Demchuk AM, Hill MD. Thrombolytic therapies for ischemic stroke: Triumphs and future challenges. Neuropharmacology. 2018;134:272-9. https://doi.org/10.1016/j. neuropharm.2017.11.010

PMid:29505787

11. Morgan E, Nwatuzor C. Starting a neurosurgical service in a Southern Nigeria rural community. Prospect, challenges, and future-the Irrua experience. Egypt J Neurosurg. 2020;35(1):4-8. https://doi.org/10.1186/s41984-020-00081-y

12. Kelly PJ, Stein J, Shafqat S, Eskey, Doherty D, Chang $Y$, et al. Functional recovery after rehabilitation for cerebellar stroke. Stroke. 2001;32(2):530-4. https://doi.org/1161/01. STR.32.2.530

13. Edlow JA, Newman-Toker DE, Savitz SI. Diagnosis and initial management of cerebellar infarction. Rev Neurol Argentina. 2009;1(2):160-1. https://doi.org/10.1016/ S1474-4422(08)70216-3 PMid:18848314

14. Tong E, Hou Q, Fiebach JB, Wintermark M. The role of imaging in acute ischemic stroke. Neurosurg Focus FOC. 2014;36(1):E3

15. Braksick SA, Himes BT, Snyder K, Van Gompel JJ, Fugate JE, Rabinstein AA. Ventriculostomy and risk of upward herniation in patients with obstructive hydrocephalus from posterior fossa mass lesions. Neurocrit Care. 2018;28(3):338-43. https://doi. org/10.1007/s12028-017-0487-3

PMid:29305758

16. Demir CF, Özdemir HH, Taşcı İ, Kaplan M, Karaboğa F. Cerebellar infarction complicated with acute hydrocephalus: A case report. Turkish J Neurol. 2012;18(4):175-6. https://doi. org/10.4274/Tnd.68915

17. Aceh Government. Governors Regulation (PERGUB) on Guidelines for Establishing and Implementing Regional Referral Hospitals in Aceh; 2015. Available from: https://www.peraturan.bpk.go.id/Home/Details/98877/ pergub-prov-nad-no-9-tahun-2015 [Last accessed on 2021 May 27].

18. Tong E, Hou Q, Fiebach JB, Wintermark M. The role of imaging in acute ischemic stroke. Neurosurg Focus FOC. 2014;36(1):E3. 